Industrial Heath, 1979, 17, 207.

\title{
LONG-TERM HEALTH CARE FOR WORKERS EXPOSED TO LOW CONCENTRATION OF LEAD
}

\author{
Kazuo SAIT0*, Toshio SAT0, Shunsaku OHNO, \\ Tsutomu TOMITA and Eimatsu TAKAKUWA \\ Department of Hygiene and Preventive Medicine, Hokkaido University \\ School of Medicine, Kita-ku, Sapporo O60 Japan
}

(Received November 12, 1979)

\begin{abstract}
Practical indicators for the health care of 64 workers exposed to a low concentration of lead were looked for from an experience of the five-year health examination carried out at six month intervals starting from the pre-employment in a modern industry producing ceramics. Blood lead levels in workers changed in relation to the amount of lead materials consumed for the production of ceramics. Furthermore, blood lead levels and delta-aminolevulinic dehydratase activity were different in each section of mixing, spray-drying, pressing, calcining, lapping, electroding and polarizing processes. Significant correlations between blood and urine lead concentrations were found when the blood lead level was higher than $20 \mu \mathrm{g} / 100 \mathrm{~m} l$ of blood. Anemic markers of red blood cell count, hematocrit, hemoglobin levels and specific gravity of whole blood did not show a significant correlation to blood lead level, urinary lead level or ALAD activity. But, a positive or negative correlation was recognized between two items among blood lead level, urinary lead level, and ALAD activity.

For these results, it is suggested that the most satisfactory examinations for diagnosis of the effect of low lead exposure are blood lead levels and ALAD activity in red blood cells. These parameters are useful for the preventing of lead poisoning.
\end{abstract}

Subclinical characteristics have been investigated about the lead workers exposed to a low concentration of lead. ${ }^{1)}$ These work environments are found in such modern industries as ceramics producing companies, well equipped press companies, etc.. The clinical findings of workers exposed to a low concentration of lead are never acute and severe. As they don't show any characteristics in appearance, some useful diagnostic items for subclinical lead poisoning are required. Remarkable lead poisoning is diagnosed by lead concentration in the blood and urine, delta-aminolevulinic acid dehydratase activity in red blood cells, coproporphyrin in urine, basophilic stippled cells of erythrocytes and the examinations for anemia such as the specific gravity of whole blood, hematocrit, hemoglobin level and red blood cell count. However, any significant changes in subclinical lead poisoning are not found in general hematological examination for anemia

* Present address : Department of Environmental Medicine, Graduate School of Environmental Science, Hokkaido University, Kita-ku, Sapporo 060 Japan. 


\section{K. SAITO, T. SATO, S. OHNO, T. TOMITA AND E. TAKAKUWA}

such as red blood cell count, specific gravity of whole blood, hemoglobin level, etc.

In this report, the authors would like to make clear what sort of biochemical findings are useful for diagnosis on subclinical lead poisoning through the health examination for five years on the workers in a ceramic industry.

\section{Subjects ANd Methods}

Sixty four male subjects aged 18 to 34 years were examined in red blood cell counts, hematocrit, hemoglobin level in the blood, the specific gravity of whole blood, deltaaminolevulinic acid dehydratase (ALAD) activity of red blood cells, and lead concentration in blood and urine together with health examination at the time of employment and as following periodical health examination at approximately six-month intervals for lead workers during a five year period. These subjects were classified and arranged by each working section to which they belonged at the time of each of the six-month health examinations. The production process consisted of seven branches: mixing process of lead materials, spray-drying, pressing, calcining, lapping, electroding and polarizing process.

For the purpose of blood examination twelve milliliters of blood were withdrawn from the Vena mediana cubiti by shringe. The specific gravity of whole blood was measured with the method of cupric sulfate, and hematocrit reading was measured with micromethod, in which a blood sample in a microglass tube was centrifuged for 5 minutes at $11,000 \mathrm{rpm}$, and the packed red cells were measured by using a graduated table chart. The activity of ALAD in erythrocytes was determined according to the method of Mauzerall and Granik ${ }^{2)}$, and calculated by the following method. The original solution, which contained $100 \mathrm{mg}$ delta-aminolevulinic acid (ALA) in $14 \mathrm{ml}$ of $0.05 \mathrm{M}$ phosphate buffer, was used to measure the ALAD activity. Zero point four milliliters of the blood samples were poured into $7 \mathrm{ml}$ glass test tubes within $4 \mathrm{hr}$ after its collection and stored for about 3 weeks at $-76^{\circ} \mathrm{C}$ in a freezer for combining destruction of blood corpuscles. Zero point two milliliters of these blood samples were taken out with a micropipet, and $0.1 \mathrm{~m} l$ of phosphate buffer $(\mathrm{pH} \mathrm{7.4)}$ and $0.1 \mathrm{ml}$ of the above ALA solution were mixed in a glass test tube. Then it was shaken for $60 \mathrm{~min}$. at $37^{\circ} \mathrm{C}$. The samples for estimation were deproteinized by adding $2 \mathrm{~m} l$ of trichlor acetic acid (TCA) to a concentration of $5 \%(\mathrm{w} / \mathrm{v})$ in a centrifuge tube, and spun at 2,500 rpm for $5 \mathrm{~min}$. for deproteinizing and stopping of the reaction. Three milliliter of Ehrlich reagent were added to $1 \mathrm{~m} l$ of the supernatant in a $20 \mathrm{~m} l$ glass tube test. Colorimetry at exactly $30 \mathrm{~min}$. after the addition was carried out at $553 \mathrm{~m} \mu$ with a spectrophotometer (Hitachi model 101). The activity of ALAD was expressed as $\mu \mathrm{mol}$ of PBG synthesized per milliliter of packed red cells per hour of incubation.

The content of $\mathrm{PbO}$ in lead materials for ceramics was $68.5 \%$. Lead concentration in the air samples at the time of each health examination was shown to be not higher than $0.55 \mathrm{mg} / \mathrm{m}^{3}$ of air in the working places: that is, $0.145-0.55 \mathrm{mg} / \mathrm{m}^{3}$ in the mixing 


\section{LONG-TERM HEALTH CARE FOR SUBCLINICAL LEAD POISONING}

section, $0.195-0.23 \mathrm{mg} / \mathrm{m}^{3}$ in the spray-drying and pressing sections, $0.04-0.06 \mathrm{mg} / \mathrm{m}^{3}$ in the calcining and polarizing sections, below $0.02 \mathrm{mg} / \mathrm{m}^{3}$ in the lapping and electroding sections. Higher lead concentrations were observed four times daily ( $15 \mathrm{~min}$. per time), when the workers measured and mixed the lead materials. Personal protective equipment consisting of masks was generally used in the mixing, spray-drying and pressing processes.

\section{RESULTS}

\section{Changes of blood lead level.}

Changes of blood lead concentrations (mean values and standard errors) in workers at a ceramic production company are shown in Fig. 1 from November, 1971 through February, 1976. Lead level in the blood since the beginning of operation had not exceeded $30 \mu \mathrm{g} / 100 \mathrm{ml}$ of blood during the past five years, as shown in Fig. 1, and it seemed to correspond to the amount of ceramic production. Blood lead levels in March 1973 showed the highest value, and this value was significantly higher than the other values. At this time ceramic production in this company was at its highest. The consumption of lead materials, particularly one month before the health examination, correlated with lead concentration in blood which showed 0.767 of correlation coefficient (Fig. 2). Those facts show that the blood lead levels correlated with the consumption of lead materials.

Blood lead levels in workers in each section are shown in Fig. 3. Average blood lead level at pre-employment was $8.5 \mu \mathrm{g} / 100 \mathrm{ml}$ of blood. The highest value was found in the section for mixing of lead materials $(30.9 \mu \mathrm{g} / 100 \mathrm{ml}$ of blood). Workers in the four sections for spray-drying, pressing, calcining and polarizing showed the following high values of 20.7 to $23.4 \mu \mathrm{g} / 100 \mathrm{ml}$ of blood. Workers in the lapping and electroding

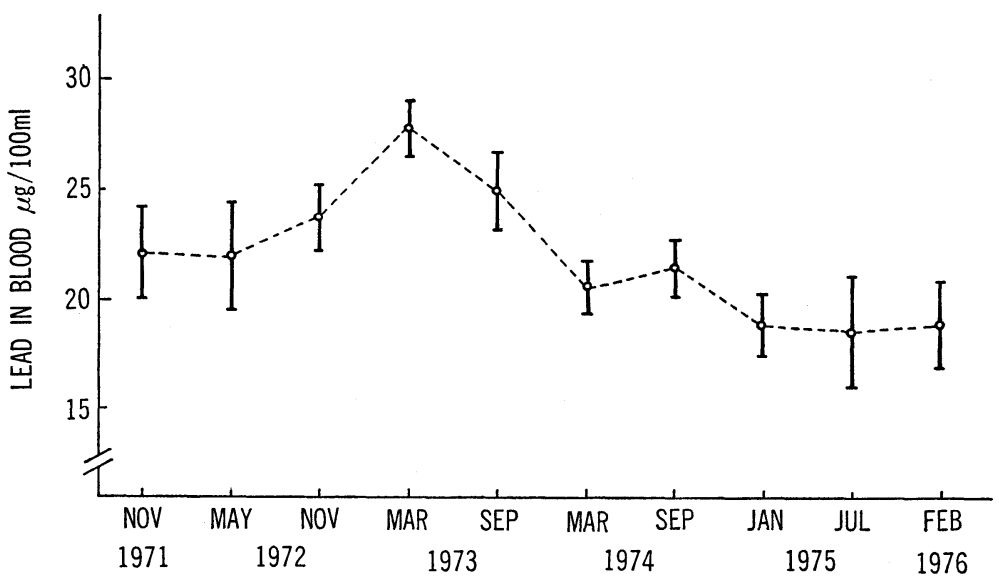

Fig. 1. Changes in blood lead levels of workers at a ceramic producing company during a five year period. (Mean \pm standard error) 
K. SAITO, T. SATO, S. OHNO, T. TOMITA AND E. TAKAKUWA

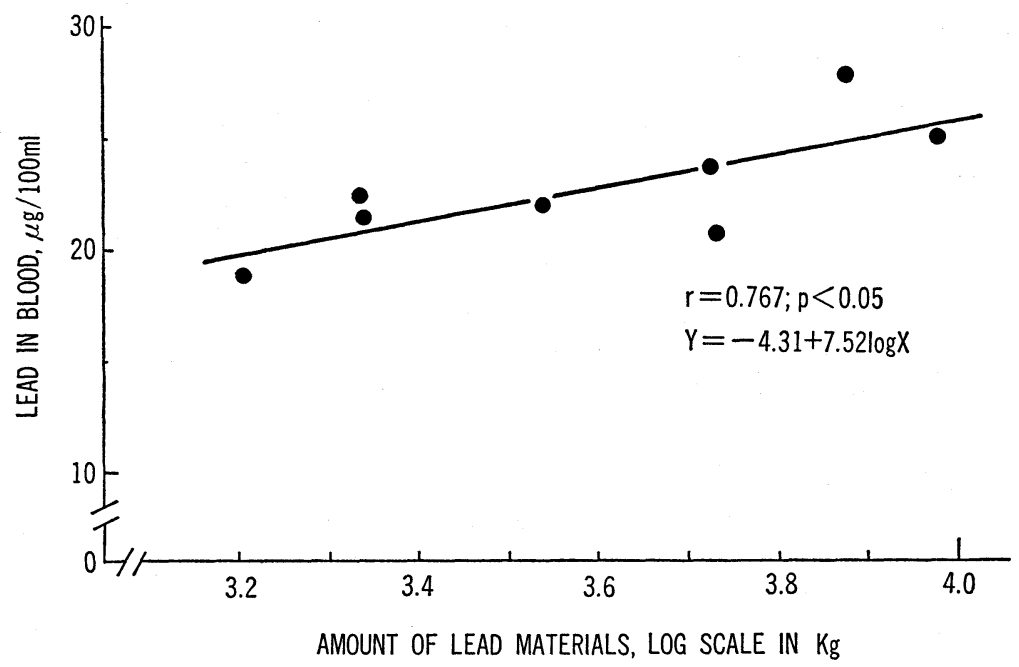

Fig. 2. Correlation between the consumption of lead material one month before health examination and blood lead levels. Eight solid points are the period from 1971 to 1974.

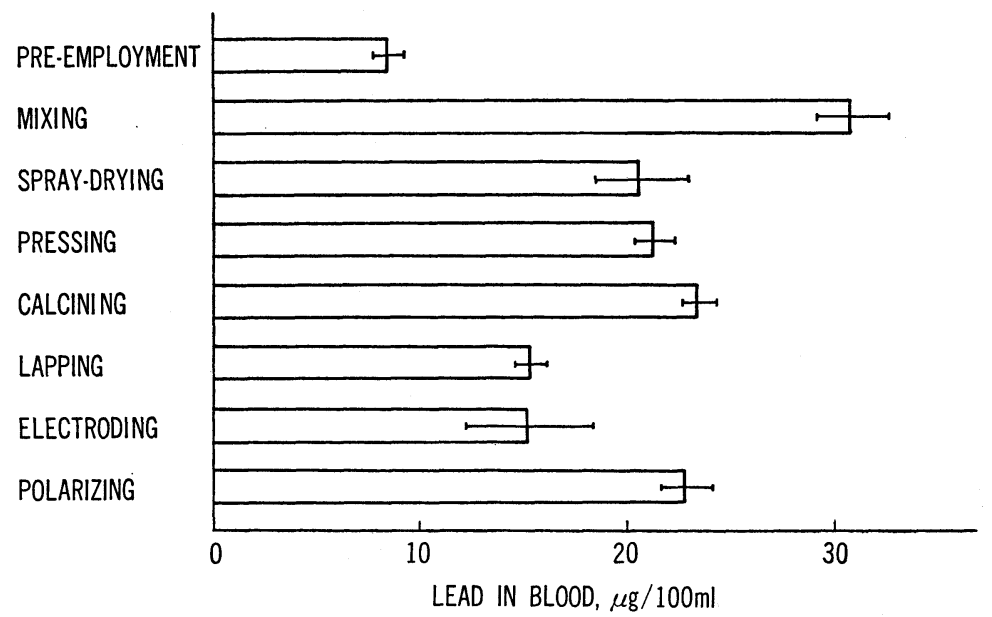

Fig. 3. Blood lead levels of workers in each process at a ceramic producing company. (Mean \pm standard error)

sections showed the lowest value of 15.3 and $15.2 \mu \mathrm{g} / 100 \mathrm{ml}$ respectively.

\section{Urinary lead concentration.}

The result of urinary lead concentration was shown in Fig. 4. Average urinary lead concentration at pre-employment was $13.8 \mu \mathrm{g} / l$ of urine. The average value of the workers in the mixing section was the highest at $51.5 \mu \mathrm{g} / l$. The following high value was found in the spray-drying, pressing, calcining and polarizing sections. The lowest value was found in the lapping and electroding sections. 
LONG-TERM HEALTH CARE FOR SUBCLINICAL LEAD POISONING

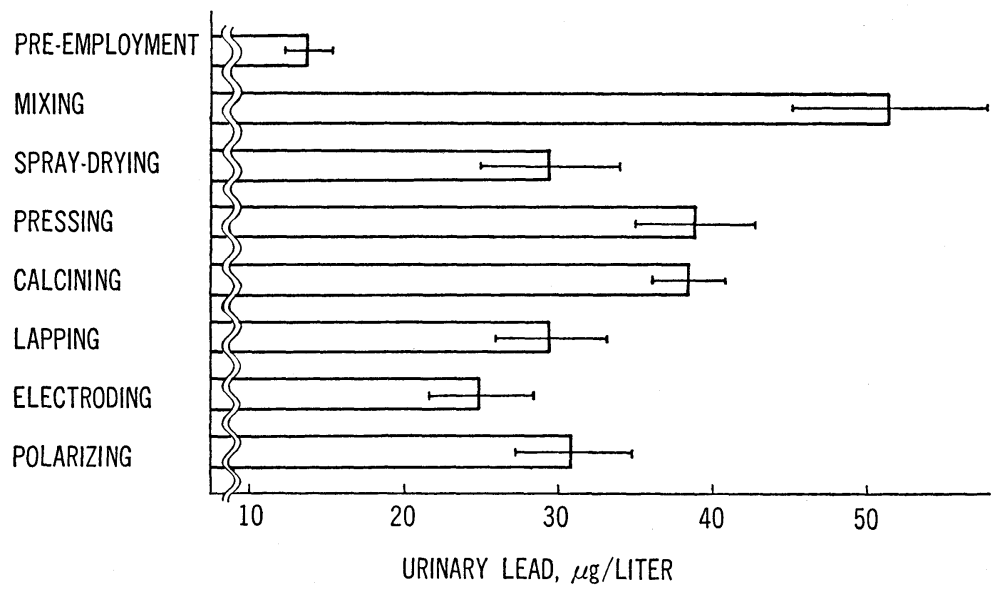

Fig. 4. Urinary lead levels of workers in each process at a ceramic producing company. (Mean \pm standard error)

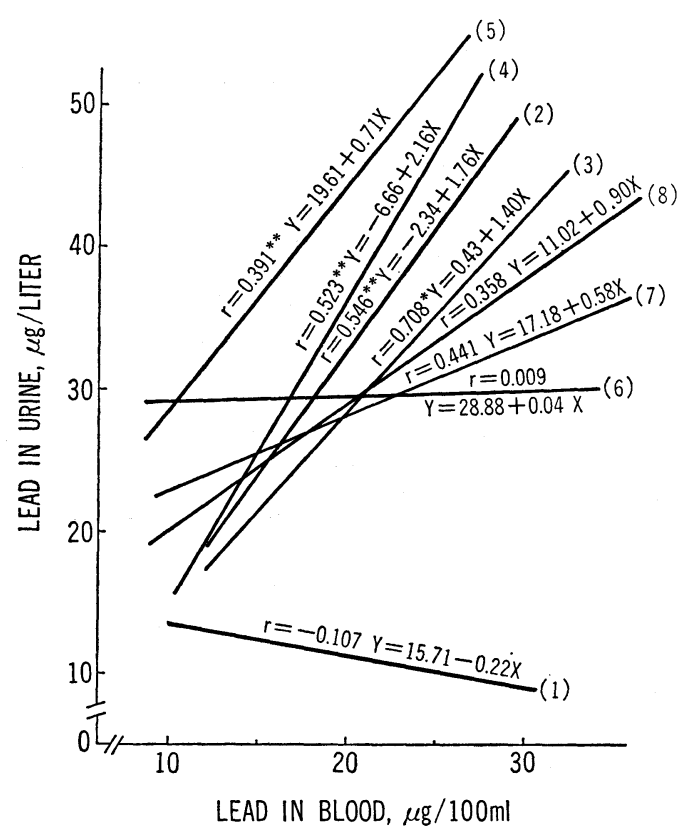

Fig. 5. Correlation coefficients and regression lines between blood and urinary lead levels.

(1): pre-employment, (2): mixing of lead materials, (3): spray-drying, (4): pressing, (5): calcining, (6): lapping, (7): electroding and (8): polarizing. $*: \mathrm{p}<$ $0.05, * *: \mathrm{p}<0.01$. 


\section{K. SAITO, T. SATO, S. OHNO, T. TOMITA AND E. TAKAKUWA}

\section{Correlation between blood and urinary lead levels.}

By comparing with the both results shown in Fig. 3 and 4, urinary lead levels were found to be proportional to blood lead levels. The correlation coefficient and the regression line between blood and urinary lead levels are shown in Fig. 5. Significant correlations were observed in the mixing of lead materials (2), spray-drying (3), pressing (4), and calcining (5) sections, where average blood lead levels in each section were higher than $20 \mu \mathrm{g} / 100 \mathrm{ml}$. The other two sections which were below $20 \mu \mathrm{g} / 100 \mathrm{ml}$ of blood did not show any significant correlation between blood and urinary lead concentrations.

\section{ALAD activity in red blood cells.}

ALAD activity levels of each section are shown in Fig. 6. Average ALAD activity at pre-employment showed the highest value $(1.29 \mu \mathrm{mol} \mathrm{PBG} / \mathrm{hr} / \mathrm{ml} \mathrm{RBC})$. Workers exposed to lead in the sections for mixing, spray-drying, pressing, calcining, lapping, electroding and polarizing showed the remarkably lower ALAD activity. ALAD activity levels of these workers were significantly different in each group. The higher lead blood levels in workers showed the lower ALAD activity levels.

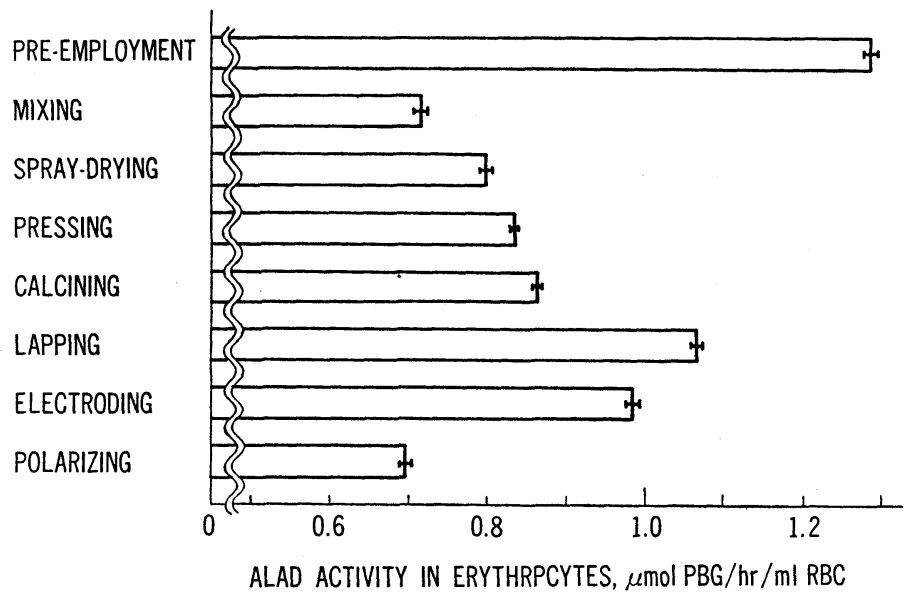

Fig. 6. ALAD activity levels of workers in each process at a ceramic producing company. (Mean \pm standard error)

5. Correlation coefficients among the diagnostic examinations for lead poisoning.

A correlation matrix of the items used for diagnosis of lead poisoning is shown in Tab. 1. Red blood cells, hematocrit, hemoglobin levels and specific gravity of whole blood showed significant correlations between the two optional factors of these items. Correlations between anemic factors and blood lead level, urinary lead level or ALAD activity did not show any significance. Although a positive or negative significant correlation was recognized between two items among blood lead level, urinary lead level, and ALAD activity, no significant correlation was observed between anemic factors and specific examinations of lead concentration in the blood, or in the urine or ALAD activity. 


\section{LONG-TERM HEALTH CARE FOR SUBCLINICAL LEAD POISONING}

Table 1. Correlation matrix of medical examination on subclinical lead poisoning.

$\mathrm{RBC}$ : red blood cells

$\mathrm{Ht}$ : hematocrit

$\mathrm{Hb}$ : hemoglobin levels

$\mathrm{Gw}$ : specific gravity of whole blood

ALAD: $\delta$-aminolevulinic acid dehydratase activity in erythrocytes

$\mathrm{PbU}$ : lead concentration in urine

$\mathrm{PbB}$ : lead concentration in blood

\begin{tabular}{lccccccc} 
& $\mathrm{RBC}$ & $\mathrm{Ht}$ & $\mathrm{Hb}$ & $\mathrm{Gw}$ & $\mathrm{ALAD}$ & $\mathrm{PbU}$ & $\mathrm{PbB}$ \\
\hline $\mathrm{RBC}$ & 1.000 & $0.569 * * *$ & $0.771^{* * *}$ & $0.170^{*}$ & -0.111 & $-0.190^{* *}$ & -0.079 \\
$\mathrm{Ht}$ & & 1.000 & $0.530^{* * *}$ & $0.379 * * *$ & $-0.222^{* *}$ & -0.115 & 0.010 \\
$\mathrm{Hb}$ & & & 1.000 & $0.389^{* * *}$ & $-0.193^{* *}$ & -0.011 & -0.018 \\
$\mathrm{Gw}$ & & & & 1.000 & -0.048 & 0.122 & 0.022 \\
$\mathrm{ALAD}$ & & & & & 1.000 & $-0.514^{* * *}$ & $-0.695^{* * *}$ \\
$\mathrm{PbU}$ & & & & & & 1.000 & $0.641^{* * *}$ \\
$\mathrm{PbB}$ & & & & & & & \\
\hline
\end{tabular}

$*: \mathrm{P}<0.10, * *: \mathrm{P}<0.05, * * *: \mathrm{P}<0.01$

\section{Discussion}

Lead poisoning in recent years has shown some characteristics which are not acute and severe, whereas the effect of low lead concentration on workers has not been frequently discussed. The data obtained in this report indicate that subclinical lead poisoning or the effect of low lead exposure below $30 \mu \mathrm{g} / 100 \mathrm{ml}$ of blood cannot be diagnosed with anemic findings such as red blood cell count, hematocrit, hemoglobin level of blood, specific gravity of whole blood etc.. Also, the effect of low lead exposure to the human body does not lead to remarkable anemia but the effect may end in changes of the enzymic activity levels related to heme-synthesis. When a significant increase in lead poisoning occurs by a high concentration of lead in the work-environment, it is clear that the effect will progress to lead anemia represented by a decrease in red blood cells, hematocrit, lowering of hemoglobin levels and a decrease in the specific gravity of whole blood. It is most important to determine the lead concentration in blood for diagnosis of lead poisoning. But, since it has been found that delta-aminolevulinic acid dehydratase (ALAD) was very sensitive to lead exposure and that its activity was inhabited even before measurable deviations occurred in these measurements, ALAD has become to be applied to diagnosing of subclinical lead poisoning and to be used to indicate an early sign of lead exposure ${ }^{3) \sim 8)}$. The authors ${ }^{9)}$ have also discussed the normal range of lead concentration in blood through the measurement of blood lead levels of traffic policemen, and have shown that any changes in ALAD activity do not appear below $15 \mu \mathrm{g} \mathrm{Pb} / 100 \mathrm{~m} l$ of blood. Recently, Paglia and Valentine ${ }^{10)}$, and Buc and Kaplan $^{11)}$ reported that pyrimidine $5^{\prime}$-nucleotidase was a sensitive and valuable index in 


\section{K. SAITO, T. SATO, S. OHNO, T. TOMITA AND E. TAKAKUWA}

individuals with a low-level exposure to lead. This enzyme is not as widely used for a complicated measurement method as compared with ALAD.

Lead concentration in blood and ALAD activity of the workers in this report seemed to be different from those to be dependent upon the lead concentration in the air of working sections. It is a useful fact that blood lead corresponds to the amount of lead materials one month before the production of ceramics. We suggested that the blood lead level responses by the stability of absorption-excretion balance one month after absorption of lead materials, is a better indicator for the exposure to lead than that which was previously said for lead concentration in urine. It has made clear blood lead concentration, ALAD activity and correlation between blood and urine lead levels are useful as the index of health care in the workers exposed to a low concentration of lead. The health care of lead workers with those having less than $30 \mu \mathrm{g} \mathrm{Pb} / 100 \mathrm{~m} l$ of blood should be considered in such forms as changing the work environment.

\section{ACKNOWLEDGEMENTS}

The authors are grateful to Kozo Niizuma for his help in data analysis. The cooperation and support of Yukio Fujiki and Yoshio Haga in the ceramics production company are gratefully acknowledged.

\section{REFERENCES}

1) Waldron, H.A. and Stofen, D. (1974). Subclinical lead poisoning, Academic Press, New York.

2) Granick, S. and Mauxerall, D. (1958). J. Biol. Chem., 232, 1119.

3) Bonsignore, D. (1966). Med. Lavoro, 57, 647.

4) De Bruin, A. and Hoolboom, H. (1967). Brit. J. Industr. Med., 24, 203.

5) Nakao, K., Wada, O. and Yano Y. (1968). Clin. Chim. Acta, 19, 319.

6) Herenberg, S., Nikkanen, J., Mellin, G. and Lilius, H. (1970). Arch. Environ. Health, 21, 140 .

7) Haeger-Aronsen, B., Addula, M. and Fristedt, B.I. (1971). Arch. Environ. Health, 23, 440.

8) Herenberg, S., Tola, S., Nikkanen, J. and Valkon, S. (1972). Arch. Environ. Health, 25, 109.

9) Saito, K., Sato, T., Sato, Y. and Niizuma, K. (1973). Ind. Health, 11, 85.

10) Paglia, D.E., Valentine, W.N. and Daiilgren, J.G. (1975). J. Clin. Invest., 56, 1164.

11) Buc, H.A. and Kaplan, J.C. (1978). Clin. Chim. Acta, 87, 49. 